J. Amer. Soc. Hort. Sci. 118(6):694-698. 1993.

\title{
Production, Growth, and Nut Quality in Pecans under Water Stress Based on the Crop Water Stress Index
}

\author{
Donald J. Garrot, Jr., ${ }^{1}$ and Michael W. Kilby ${ }^{2}$ \\ Department of Plant Sciences, University of Arizona, Tucson, AZ 85721 \\ Delmar D. Fangmeier ${ }^{3}$ \\ Department of Agricultural and Biosystems Engineering, University of Arizona, Tucson, AZ 85721
}

Stephen H. Husman ${ }^{4}$

Cooperative Extension, University of Arizona, Tucson, AZ 85721

Andrew E. Ralowicz 5

Department of Plant Sciences, University of Arizona, Tucson, AZ 85721

Additional index words. irrigation, crop water stress index, water-use efficiency, yield efficiency, Carya illinoensis

\begin{abstract}
The crop water stress index (CWSI), based on the relationship between the canopy temperature of a well-watered plant in full sunlight and the atmospheric water content, numerically quantifies water stress. A 4-year study was established to determine the long-term effect of water application levels on production, nut quality characteristics, and growth of pecans [Carya illinoinensis (Wangenh.) C. Koch cv. Western Schley]. Highest yields were attained when trees were relatively nonstressed (CWSI $\leq \mathbf{0 . 0 8}$ ). Trees subjected to moderate water stress before irrigation (CWSI $\geq 0.20)$ showed reduced yield, nut weight, and tree growth, although water-use efficiency increased. With water management practices resulting in maximum yield, nut size, and tree growth $($ CWSI $\leq 0.08)$, tree water use varied up to $44 \%$ in the same orchard, depending on crop load and yearly climatic variations.
\end{abstract}

Increasing costs and decreasing supplies of water in the southwestern United States are forcing growers to be more water conscious if a profit is to be realized. Typical irrigation scheduling techniques have relied on indirect methods: soil moisture measurements, soil tensions, estimated evapotranspiration, crop growth patterns, and fixed schedules. Direct indications of plant water stress have required difficult measurements of leaf water potential, leaf transpiration rates or stomatal resistance, and crop color. The crop water stress index (CWSI) has been proposed as a noninvasive direct approach based on canopy temperature.

Two crop water stress indices were developed at the U.S. Water Conservation Laboratory, Phoenix, Ariz. The empirical CWSI approach uses real-time canopy temperatures, measured with an infrared thermometer, and the corresponding absolute air moisture status [vapor pressure deficit (VPD)] to determine the water stress of a particular plant or field (Idso et al., 1981a). When stomata are open, atmospheric $\mathrm{CO}_{2}$ enters the leaf and water vapor escapes from the leaf into the atmosphere, evaporating and cooling the leaf tissues. The hotter and dryer the air (greater VPD), the faster the water will evaporate, and the greater the cooling effect on the leaf tissues. The CWSI, according to Idso et al (1981a), is calculated as

Received for publication 13 Nov. 1992. Accepted for publication 30 Jan. 1993. Research conducted at Continental, Ariz., in cooperation with Farmers Investment Corporation, Sahuarita, Ariz. Use of mention of trade names implies neither endorsement of the products named nor criticism of similar products not named. We gratefully acknowledge Farmers Investment Corporation, Sahuarita, Ariz., for supplying the test site, labor, equipment, and financial support; and Santa Cruz Valley Pecan Co., Sahuarita, Ariz., for assistance with the collection of nut quality data for the duration of this research. The cost of publishing this paper was defrayed in part by the payment of page charges. Under postal regulations, this paper must hereby by marked advertisement solely to indicate this fact.

${ }^{1}$ Extension Plant-Water Relations Specialist.

${ }^{2}$ Extension Horticulturist.

${ }^{3}$ Professor.

${ }^{4}$ Maricopa County Extension Field Crops Agent.

${ }^{5}$ Research Associate.

$$
\mathrm{CWSI}=\left(\mathrm{T}_{\mathrm{c}}-\mathrm{T}_{\mathrm{a}}-\mathrm{D}_{2}\right) /\left(\mathrm{D}_{1}-\mathrm{D}_{2}\right)
$$

where $T_{c}$ and $T_{a}$ are the average canopy temperature and air temperature $\left({ }^{\circ} \mathrm{C}\right)$, respectively; and $\mathrm{D}_{2}$ and $\mathrm{D}_{1}$, the predicted respective minimum and maximum values of $\left(T_{c}-T_{a}\right)$ at a specific VPD ( $\mathrm{kPa}$ ) from the baseline equation. The CWSI was defined by Jackson et al. (1981) as

$$
\mathrm{CWSI}=1-\mathrm{E} / \mathrm{E}_{\mathrm{p}}
$$

where $\mathrm{E}$ equals the actual evapotranspiration and $\mathrm{E}_{\mathrm{p}}$ is the potential evapotranspiration rate of the leaf or canopy. This latter method accounts for variations in environmental conditions, whereas the former (Idso et al, 1981a) must duplicate closely the conditions under which the calibration curve was derived.

Therefore, it is now possible to predict the temperature of a leaf at a specific VPD when soil water is not limiting the ability of the plant to transpire. As soil moisture is depleted, continually decreasing amounts of water vapor flow out of the leaf. This decline decreases the potential evaporative cooling effect on the leaf tissues, which increases the leaf or canopy temperature (measurable with an infrared thermometer). When differences between the leaf or canopy temperatures and the air temperatures $\left(T_{c}-T_{a}\right)$ are regressed on the atmospheric VPD dam (Idso et al., 1981a), a CWSI value can be calculated for that plant, group of plants, or canopy. A CWSI value near 0.0 indicates no water stress, while one approaching 1.0 indicates severe water stress. The relationship between $\mathrm{T}_{c}-\mathrm{T}_{\mathrm{a}}$ and VPD or the "CWSI baseline" described previously for pecans (Sammis et al., 1986, 1987) did not apply to our field site.

Mature pecan leaves do not wilt, and therefore do not exhibit any visible signs of water stress until leaf or fruit drop (Miyamoto, 1983). Furthermore, water use varies with tree size, tree density, and weather conditions. Rainfall and variable soil textures also complicate irrigation management (Miyamoto, 1983). Pecan trees require nonstressed conditions from pollination in early May to 
shell hardening in late August to achieve maximum nut size (Kilby, 1980). Kilby (1980) also reported that water stress during the latter part of the growing season resulted in decreased nut quality.

The use of the CWSI to schedule irrigations and the subsequent effects on production as a function of varying CWSI irrigation scheduling values have been described for various crops (Garrot, 1984; Garrot et al., 1990a, 1990b; Husman et al., 1990; Idso et al., 1981b; Nielsen, 1990; Nielsen and Gardner, 1987; Wanjura et al., 1990). The CWSI has shown a close relationship to the amount of water in the root zone of wheat (Triticum aestivum L.) (Jackson et al., 1981), the plant water potential in alfalfa (Medicago sativa L.) and wheat (Idso et al., 1981a, 1981b); the plant water potential of cotton (Gossypium hirsutum L.) (Pinter and Reginato, 1982), and the photosynthetic rates and leaf diffusion resistance of cotton (Idso et al., 1982).

Our experiment was designed to determine if hand-held infrared thermometers that measure the crop water stress index can be used to quantify water stress of a commercial pecan orchard. From a research standpoint, we wanted to induce measurable increasing increments of water stress to establish water stress treatments using the CWSI technique. From a research and producer perspective, we wanted to determine the effects of long-term (4 years) water stress on nut production, nut quality, and tree growth. From a producer standpoint, we wanted to determine if the CWSI technique, using a hand-held infrared thermometer, is a viable tool to assist irrigation managers in making decisions about pecan orchard irrigation.

\section{Materials and Methods}

Sixteen rows of a 32-ha pecan orchard planted in 1967 with 'Western Schley' trees were selected as the test site. Trees in these rows were originally on $5 \times 10-\mathrm{m}$ spacings, and thinned in 1986 to $10 \times 20$-m spacings (containing from 22 to 37 trees per row). In 1988 , every fourth tree within the row was removed (containing from 15 to 28 trees per row), then the orchard was thinned further to $20 \times 20$-m spacings in 1989 (containing 11 to 19 trees per row). The soil was a Pima clay loam (mixed, thermic Typic Torrifluvent). The 16 rows were randomized into four replications of four transpiration-reduction treatments (increasing CWSI values before irrigation) in a randomized complete block design. Three of the four treatments were scheduled for irrigations with CWSI estimates of $0.15,0.30$, and 0.45 (wet, medium, and dry plots, respectively), while the fourth treatment was grower-irrigated and also CWSI-monitored.

Grower irrigation frequency was based on calendar scheduling, about every 14 days, supplemented with soil sampling using the feel method. Basic cultural practices implemented by the grower included annual $\mathrm{N}$ and $\mathrm{Zn}$ applications, pest control, and weed management. Each year pollen was disseminated by air at the rate of $35 \mathrm{~g} \cdot \mathrm{ha}^{-1}$ every 4 days during stigma receptivity. Nitrogen was applied yearly as a liquid in the irrigation water, beginning at budbreak, and in each irrigation until the estimated requirement was met. The method used to estimate $\mathrm{N}$ requirement was equivalent to $4.5 \mathrm{~kg} \mathrm{~N} / 45 \mathrm{~kg}$ of expected nut yield. Zinc was applied yearly to foliage, five times at 2 -week intervals, with the first application beginning with budbreak at a rate of $9.0 \mathrm{~kg} \cdot \mathrm{ha}^{-1}$. The weed management program consisted of a combination of glyphosate and mowing. Orchards were mowed before harvest to facilitate ground pick-up techniques. Insects, predominantly yellow and black pecan aphids, were controlled with a single yearly application of malathion and 5000 lacewing larvae/ha.
CWSI values were calculated from the average of two infrared canopy temperature measurements within each plot, about oneand two-thirds into the field from the irrigation ditch. Attempts were made to irrigate the three transpiration reduction treatments at low to moderate water stress levels. Each replication was bordered by dikes on either side to form a 9-m-wide basin. Rows received the same treatment for the duration of the test (1987 to 1990). About 130 to $150 \mathrm{~mm}$ of water was applied to each basin with each irrigation.

We used an infrared thermometer (Model 112, Everest Interscience, Inc., Fullerton, Calif.) with a $15^{\circ}$ germanium lens. Two directional readings were taken on the sunlit south side of the tree canopy looking up to the east and then to the west at each site. Care was taken to not include background sky in the infrared thermometer field of view. About three tree canopies were included in the field of view for each infrared temperature measurement, representing $\approx 32 \%$ to $55 \%$ of the trees in a row, depending on row length and tree spacing. Infrared canopy temperature measurements were collected between 1100 and 1500 HR twice weekly when skies were clear. Vapor pressure deficit (VPD) was measured in full sunlight $2 \mathrm{~m}$ above ground level between rows with an aspirated psychrometer (Psycrho-Dyne model, Environmental Tectonics Corp., Southhampton, $\mathrm{Pa}$.) at 15-min intervals.

In 1987, soil moisture measurements were taken with a neutron moisture hydroprobe (Model 503DR, Campbell Pacific Nuclear, Martinez, Calif.) to a depth of $2.1 \mathrm{~m}$ in $30-\mathrm{cm}$ increments at each infrared measurement site in each plot. These data were collected weekly before an irrigation.

The 16 plots (rows) were individually machine-harvested by the grower on 20 Jan. 1988, 19 Jan. 1989, 9 Jan. 1990, and 25 Feb. 1991. Three random $0.5-\mathrm{kg}$ subsamples from each plot were graded for nut quality by a commercial shelling plant (Santa Cruz Valley Pecan Co., Sahuarita, Ariz.). Percent saleable (edible) kernels was the summation of percent good, percent amber, and percent light nuts. Inedible kernels included nuts that were wafered, rotted, damaged by insects, or had pregerminated. Data were recorded for irrigation practices (number of irrigations, amount of water applied) and yield components (yield and nut weight). Tree growth was based on measurements of trunk circumference on each tree. Trunk circumference was measured $500 \mathrm{~mm}$ above ground level each January of 1987 through 1991. Yearly increases in trunk circumference were converted to cross-sectional area. Yield efficiency was calculated as the kilograms of nuts per square centimeter of trunk cross-section. Water-use efficiency was calculated as kilograms of nuts produced per cubic meter of irrigation water. Relative percentages of yield, nut size, and growth were calculated by dividing an individual characteristic datum by the maximum value of that character within that year, and expressing the fraction as a percentage. This procedure normalized the fluctuations of yield and growth caused by irregular bearing. In 1987 and 1988, nut drop was measured, following the conclusion of August drop, by counting fruit abscission scars in comparison to the number of fruitlets on 10 fruiting terminals per tree in each plot. Leaf $\mathrm{N}$ concentration was determined from laboratory analysis of leaflets collected from each tree in each plot. Two leaflets were collected from the mid-petiole position of a leaf located in the middle of the current-season's growth. Leaflets were collected from five terminals per tree per plot and pooled by plot. Nitrogen was determined by the Kjeldahl method (Bremner and Mulvaney, 1982).

Analysis of variance was conducted on the complete model as a randomized complete block design with repeated sampling in time using the General Linear Models procedure in SAS (SAS, 
1991). Linear, quadratic, and cubic trend analysis of yield, growth, and water-use data (dependent variables) on CWSI, values (independent variable) were performed by year and for the combined 4 years of data.

\section{Results and Discussion}

Analysis of our canopy temperature data produced a baseline where $\mathrm{y}=-0.86-0.50 \mathrm{VPD}(\mathrm{kPa})$. The published baseline, where $\mathrm{y}=0.03-0.59 \mathrm{VPD}(\mathrm{kPa})$ with a 4.0C upper limit (Sammis et al., 1986, 1987), frequently gave CWSI values that exceeded the theoretical lower limit of 0.0 (no water stress), resulting in negative CWSI values after irrigations were applied. Our baseline was calculated from 22 values collected 3 to 6 days following an irrigation for all the treatments. The slopes of the two lines were quite similar, but the intercepts were different, with the latter being a negative number. Nielsen (1990) determined from analysis of his data that the CWSI baseline of soybean (Glycine max L.) published by Idso (1982) did not work for his conditions. Nielsen (1990) calculated a new baseline from his historical field data, which eliminated CWSI values that exceeded the theoretical limits of 0.0 (no water stress) and 1.0 (complete water stress). This phenomenon (different CWSI baselines) does not appear to be true for all crop species investigated. Investigations on short staple cotton and durum wheat (Triticum durum Desf.) showed no differences in the CWSI baselines from field trials compared to the baselines of Idso (1982). These trials, however, also were conducted in Arizona, where Idso computed his baselines.

The most probable explanation for the discrepancy between our pecan baseline and that of Sammis et al. (1986, 1987) will be discussed briefly. Theoretically, when the atmosphere is saturated, no evaporative cooling effect on the leaf should be measurable, and the temperature of the foliage should be greater than or equal to that of ambient air (Idso et al., 198 la). The wide angle 15" field of view of the infrared thermometer averaged both the sunlit and shaded portions of about three entire tree canopies in one measurement. Shaded areas of the canopy, also included in the field of view, are cooler than the sunlit areas and lower the overall temperature derived from the infrared measurement and might be responsible for the negative intercept. Idso (1982) reported that shaded plants had baseline intercepts as much as 4.0C lower than sunlit plants, however, the baselines had similar slopes. The 0.9C difference between the seasonal baseline from this test and the published baseline is well within the 4.0C difference previously reported. Also, lack of baseline data in the very low VPD range combined with the $r^{2}$ value of 0.70 for the baseline might account for the negative intercept due to scatter or because the line may be curvilinear at very low VPDs (Idso et al., 1986).

Because the orchard-specific baseline is an actual measure fit for our test under orchard conditions, it was used to calculate the CWSI for the 1987 through 1990 growing seasons. Tree density and planting direction affect the amount of shade included in the infrared measurement. Therefore, different orchards would be expected to have different baselines.

The average CWSI, was calculated from the CWSI values measured 1 to 2 days before an irrigation. For example, in 1987, the wet treatment (Table 1, water level 2) represents the average of 11 values ( 11 irrigations needed), the medium treatment an average of seven values (seven irrigations needed), and so forth. An error of \pm 0.05 CWSI units is commonly encountered when collecting CWSI field measurements over large areas and time increments. Subsequently, there were few differences between transpiration reduction levels within the \pm 0.05 -unit error for most of the vari- ables presented. For example, a comparison between CWSI, values for wet or nonstressed (water level 2) and grower (water level 1) treatments are within 0.04 unit of each other in 1987 and the similarity between these CWSI values is reflected in both yield and nut weight.

Data pooled for the 4 years showed that yield was reduced by $5 \%$ to $24 \%$ when the quantity of water applied was reduced from $5 \%$ to $52 \%$ relative to water level 1 (Table 1 ). Nut weight was reduced $8 \%$ and trunk growth $27 \%$ when water applied was decreased by $52 \%$. Saleable and inedible kernel percentages and yield efficiency were unaffected by treatment. The pooled results indicate that WUE increases with increasing water stress; however, the economics of commercial production and the reduction in cumulative yield, reduced tree growth, and reduced nut weight do not justify purposely water-stressing pecan trees. In geographical areas where water allocation is limited to levels that will result in less-than-optimum production, controlled imposition of water stress to reduce water use might be implemented economically.

The highest pecan yields were attained when irrigations were scheduled at CWSI, $\leq 0.08$ unit in all 4 years (Table 1). Moderate increases in water stress (CWSI $\geq 0.20$ unit) resulted in lower yields in all years, but only significantly in 1988 and 1990. The need for a relatively nonstressed condition to produce maximum pecan yields agrees with work published previously (Kilby, 1980). The total amount of water applied to maintain a water stress level 10.14 CWSI, unit was greatest in 1988. In 1988, more applied water was needed to produce CWSI, values below 0.14 unit than the water applied to CWSI, treatments 10.14 unit in 1987, 1989, and 1990, suggesting that trees with a heavy crop load, as in 1988, require more water. Therefore, the seasonal water use is modified according to the crop load on the tree. Water stress levels 10.14 CWSI, unit produced the heaviest nuts (Table 1), also in agreement with results published previously (Kilby, 1980). The high yields produced in 1988 reduced nut weight by $11 \%$ when compared with 1987 for the same CWSI, level (0.14 unit). Further, nut weight in treatments 10.14 CWSI, unit in 1988 were $15 \%$ and $8 \%$ lower than in 1989 and 1990, respectively, for similar CWSI, treatments in those years. Increasing irrigation water application by $44 \%$ from 1987 to 1988 did not prevent a reduction in nut size in 1988. In all years, except for 1988 (the highest production year), the lowest CWSI treatments resulted in the highest nut weights. In 1988, lowering the CWSI from 0.14 to 0.10 unit did not overcome the reduction in nut weight, although the 0 . lo-unit treatment produced a significantly higher yield. We suggest that possibly the crop load, not water stress, is the overriding factor on nut weight when fruit set is high, although this hypothesis was not tested in this experiment.

The pooled data indicate a quadratic association of the CWSI with yield, trunk growth, nut weight, and WUE (Table 1). Limiting transpiration reduced yield, nut weight, and tree growth when yield and growth data were normalized (expressed as relative percentages of the criterion), and regressed on plant transpiration, as estimated by CWSI, values (Fig. 1). The slopes of regression equations (Fig. $1 \mathrm{a}-\mathrm{c}$ ) indicate that growth, i.e., increase in trunk diameter, was most affected by increasing CWSI, values, or decreasing transpiration, compared to yield or nut size.

The effect of CWSI, levels on pecan tree percentage of fruit drop was assessed in 1987 and 1988, and percentage of 1eaf $\mathrm{N}$ was quantified in 1987, 1988, and 1989. Neither the percentage of fruit drop (grand mean $=31.16 \%, \mathrm{cv}=8.7 \%$ ) nor the percentage of leaf $\mathrm{N}$ (grand mean $=2.43 \%, \mathrm{cv}=4.4 \%$ ) were correlated with water stress levels (detailed data not shown).

As reported in an earlier preliminary field trial (Garrot et al., 
Table 1. Means of crop water stress index (CWSI) levels, irrigation practices, and yield components for pecans at Continental, Ariz., from 1987 to 1990.

\begin{tabular}{|c|c|c|c|c|c|c|c|c|c|c|}
\hline \multirow{2}{*}{$\begin{array}{l}\text { Water } \\
\text { level }\end{array}$} & \multirow[b]{2}{*}{$\mathrm{CWSI}_{\mathrm{I}}^{\mathrm{z}}$} & \multirow{2}{*}{$\begin{array}{c}\text { Yield } \\
\left(\mathrm{kg}^{\circ} \mathrm{ha}^{-1}\right)\end{array}$} & \multirow{2}{*}{$\begin{array}{c}\text { Trunk } \\
\text { growth }^{\mathrm{y}}(\%)\end{array}$} & \multirow{2}{*}{ 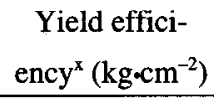 } & \multirow{2}{*}{$\begin{array}{l}\text { Nut wt } \\
\text { (g/nut) }\end{array}$} & \multicolumn{2}{|c|}{ Kernels } & \multirow{2}{*}{$\begin{array}{c}\text { No. } \\
\text { irrigations }\end{array}$} & \multirow{2}{*}{$\begin{array}{c}\text { Water } \\
\text { applied (mm) }\end{array}$} & \multirow{2}{*}{$\begin{array}{c}\text { WUE } \\
\left(\mathrm{kg} \cdot \mathrm{m}^{-3}\right) \\
\end{array}$} \\
\hline & & & & & & Saleable & Inedible & & & \\
\hline \multicolumn{11}{|c|}{1987} \\
\hline $1^{\mathrm{v}}$ & 0.08 & 1582 & 2.4 & 0.37 & 6.6 & 58.8 & 0.2 & 9 & 1372 & 0.12 \\
\hline 2 & 0.12 & 1584 & 2.6 & 0.34 & 6.6 & 59.0 & 0.0 & 11 & 1676 & 0.09 \\
\hline 3 & 0.20 & 2448 & 2.2 & 0.32 & 6.3 & 58.8 & 0.1 & 7 & 1067 & 0.15 \\
\hline 4 & 0.27 & 1383 & 2.0 & 0.32 & 6.1 & 58.6 & 0.2 & 4 & 686 & 0.20 \\
\hline Linear & & $N \mathbf{S}^{\mathrm{u}}$ & NS & NS & NS & NS & NS & & & $*$ \\
\hline Quadr & & NS & NS & NS & $*$ & NS & NS & & & $* * *$ \\
\hline \multicolumn{11}{|c|}{1988} \\
\hline 1 & 0.10 & 3749 & 4.6 & 0.74 & 5.9 & 56.8 & 0.6 & 13 & 1981 & 0.19 \\
\hline 2 & 0.14 & 3490 & 4.1 & 0.72 & 6.0 & 58.4 & 0.5 & 13 & 1981 & 0.18 \\
\hline 3 & 0.29 & 3098 & 3.6 & 0.64 & 5.7 & 57.4 & 0.9 & 9 & 1372 & 0.23 \\
\hline 4 & 0.50 & 2616 & 2.6 & 0.57 & 5.6 & 57.6 & 0.7 & 7 & 1067 & 0.25 \\
\hline Linear & & NS & NS & NS & NS & $*$ & NS & & & NS \\
\hline Quadr & & $* *$ & $* *$ & $* *$ & $* *$ & NS & NS & & & $* *$ \\
\hline \multicolumn{11}{|c|}{1989} \\
\hline 1 & 0.14 & 1350 & 4.5 & 0.34 & 6.9 & 52.8 & 3.8 & 12 & 1524 & 0.09 \\
\hline 2 & 0.14 & 1151 & 4.9 & 0.29 & 6.8 & 52.2 & 4.5 & 13 & 1651 & 0.07 \\
\hline 3 & 0.28 & 1045 & 3.0 & 0.28 & 6.4 & 53.4 & 2.7 & 8 & 1016 & 0.10 \\
\hline 4 & 0.41 & 1064 & 3.1 & 0.29 & 6.0 & 53.7 & 2.6 & 7 & 889 & 0.12 \\
\hline Linear & & NS & NS & NS & NS & NS & NS & & & NS \\
\hline Quadr & & NS & $* *$ & NS & $* * *$ & NS & $*$ & & & $*$ \\
\hline \multicolumn{11}{|c|}{1990} \\
\hline 1 & 0.02 & 1940 & 5.4 & 0.67 & 6.5 & 55.0 & 3.4 & 10 & 1524 & 0.13 \\
\hline 2 & 0.19 & 2005 & 5.1 & 0.68 & 6.3 & 56.2 & 1.5 & 5 & 762 & 0.26 \\
\hline 3 & 0.38 & 1477 & 4.6 & 0.55 & 6.3 & 55.1 & 2.2 & 4 & 610 & 0.24 \\
\hline 4 & $0.33^{\mathrm{u}}$ & 1490 & 4.7 & 0.55 & 6.3 & 54.4 & 4.0 & 3 & 457 & 0.33 \\
\hline Linear & & NS & NS & NS & NS & NS & NS & & & $* *$ \\
\hline Quadr & & $* *$ & $* *$ & $*$ & NS & NS & NS & & & $* *$ \\
\hline Cubic & & NS & NS & NS & NS & NS & NS & & & $* *$ \\
\hline \multicolumn{11}{|c|}{ 1987-1990 pooled } \\
\hline 1 & 0.08 & 8620 & 16.9 & 0.53 & 6.5 & 55.8 & 2.0 & 44 & $6.4^{t}$ & 0.13 \\
\hline 2 & 0.15 & 8229 & 16.7 & 0.51 & 6.4 & 56.4 & 1.6 & 42 & 6.1 & 0.15 \\
\hline 3 & 0.29 & 7068 & 13.4 & 0.45 & 6.1 & 56.2 & 1.5 & 28 & 4.1 & 0.18 \\
\hline 4 & 0.38 & 6552 & 12.4 & 0.43 & 6.0 & 56.1 & 1.9 & 21 & 3.1 & 0.23 \\
\hline Linear & & NS & NS & NS & NS & NS & NS & & & NS \\
\hline Quadr & & $* * *$ & $* * *$ & NS & $* * *$ & NS & NS & & & $* * *$ \\
\hline Cubic & & NS & NS & NS & NS & NS & NS & & & $* * *$ \\
\hline
\end{tabular}

${ }^{\mathrm{z} A v e r a g e ~ C W S I}$ value at irrigation, dependent variable.

${ }^{y}$ Measured as the yearly increase in trunk diameter, expressed as a percentage.

xYield efficiency, kilograms of nuts per square centimeter of trunk.

wWater-use efficiency, kilograms of nuts per cubic centimeter of irrigation water.

water level 1 denotes grower-monitored plots.

"Highest water stress incurred before summer rains (no irrigations by CWSI).

Total water applied, ha/m.

ns,****,*** Nonsignificant or significant at $P \leq 0.05 .0 .01$, or 0.001 , respectively.

1987), determination of water use with the neutron probe was impractical. The alluvial soil had multiple clay and sand layers throughout the $2.1-\mathrm{m}$ profile. Field capacities ranged from 33 to $127 \mathrm{~mm}$ in the top $30 \mathrm{~cm}$ of soil within an irrigation border, and were $51 \mathrm{~mm}$ per $30 \mathrm{~cm}$ in the $30-$ to $60-\mathrm{cm}$ depth of the profile. On average, $45 \%$ of the total water-holding capacity could be depleted from the 2.1-m profile with no reduction in yield or quality in the wet and grower treatments. Previous reports indicated that $60 \%$ to $75 \%$ of available soil moisture could be depleted before irrigation without reducing nut quality (Miyamoto, 1983).

When large orchards are flood-irrigated, the water application depth is controlled by the capabilities of the irrigation system rather than soil moisture conditions. Whether the field is level, the length of the run, the water applied, and the height of any groundcover greatly affect irrigation efficiency. As most of the water us depleted from the top meter of the soil profile by pecans (Miyamoto, 1983), soil moisture depletions usually are less than the water depths normally achieved after irrigation. 

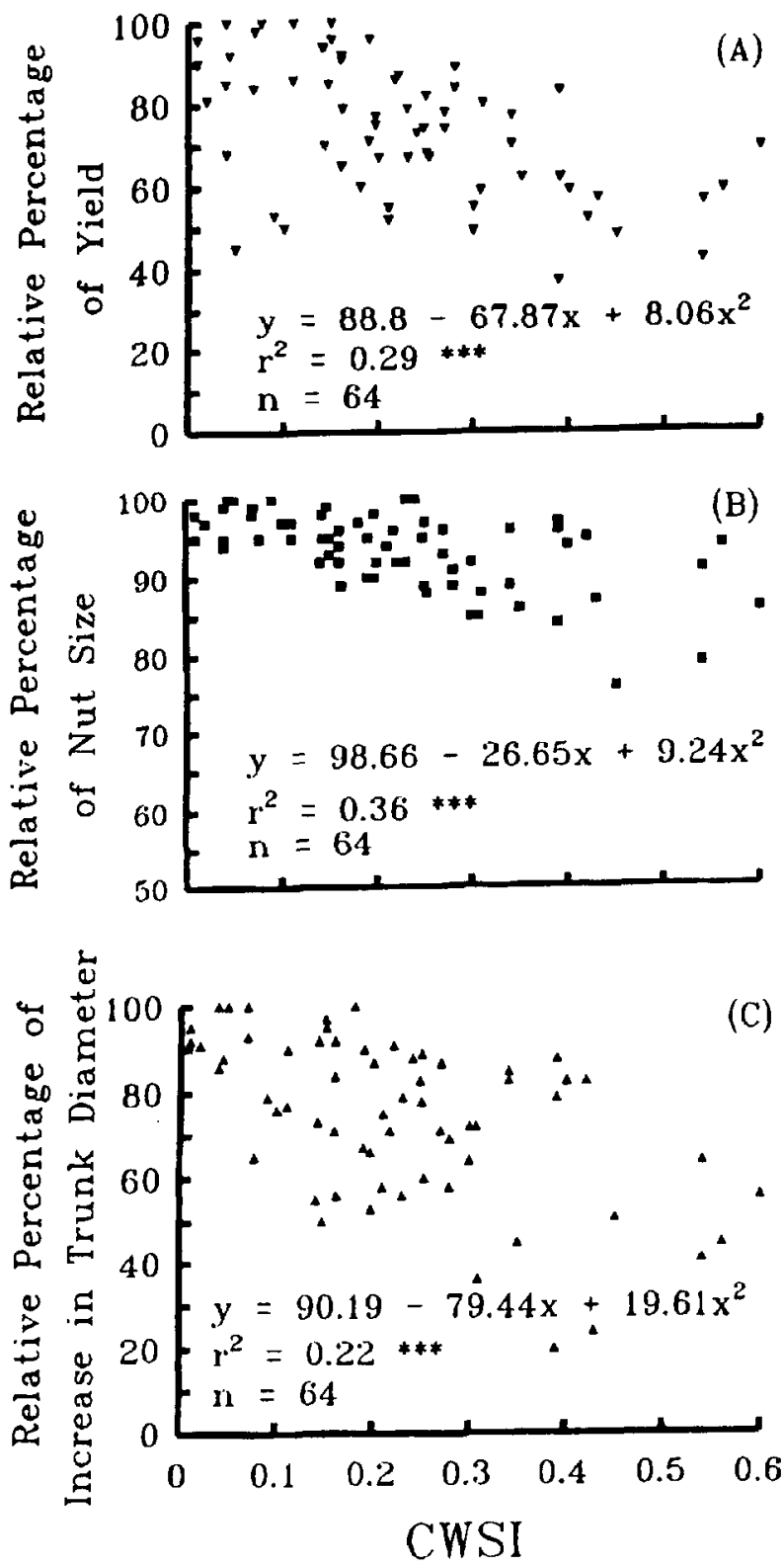

Fig. 1. Relationships between $\mathrm{CWSI}_{\mathrm{I}}$ and $(\mathbf{A})$ relative percentage of yield, $(\mathbf{B})$ relative percentage of nut size, and $(C)$ relative percentage of increase in trunk diameter on pecans grown at Continental, Ariz., from 1987 to $1990(n=64)$. Asterisks (***) denote significance at $P \leq 0.001$. CWSI is the average CWSI value just before irrigation.

The successful use of the CWSI technique, using hand-held infrared thermometers, requires the user to have a thorough knowledge of CWSI theory, and variability with its use between orchards. A crop water stress index (CWSI) can be calculated for pecans, although the baseline appears to be orchard-specific based on the amount of shading included in the field of view of the infrared temperature measurement and the direction of planting. A moderate increase in water stress (i.e., increasing CWSI or decreasing transpiration) before irrigation resulted in: a) decreased nut production $\left.\left(\mathrm{kg} \cdot \mathrm{ha}^{-1}\right), \mathrm{b}\right)$ decreased nut size $\left.(\mathrm{g} / \mathrm{hut}), \mathrm{c}\right)$ decreased tree growth (percent increase in trunk diameter); d) decreased water applied (ha/m); e) decreased number of irrigations; and f) increased water use efficiency ( $\mathrm{kg}$ nuts $/ \mathrm{m}^{3}$ of water). Trees required $44 \%$ more water during the high-yielding relative to the low-yielding year for maximum production and growth. Therefore, it is very important to know when to schedule irrigations in the high producing years. Highest pecan yields occurred when orchard irrigations were scheduled within 1 to 2 days of CWSI levels 10.08 unit. Water stress levels 20.20 CWSI, unit decreased pecan yields, nut weights, tree growth, and yield efficiencies. Reduced nut weight cannot be overcome in the high production years by increasing applied water. Within the high production year, irrigating at lower CWSI stress levels ( 0.10 vs. 0.14 unit $)$ did not overcome the loss in nut weight, although trees in the 0.10-unit stress level had higher nut yield.

\section{Literature Cited}

Bremner, J.M. and C.S. Mulvaney. 1982. Nitrogen-total. Methods of soil analysis. Part 2. 2nd ed. Agronomy 9:595-624.

Garrot, D.J., Jr. 1984. Water and stress effects on growth and rubber accumulation in guayule (Parthenium argentatum Gray). PhD Diss., Univ. of Arizona, Tucson. [Diss. Abstr. 85-4120.]

Garrot, D.J., Jr., M.W. Kilby, D.D. Fangmeier, and S.H. Husman. 1987. Water stress effects on pecan growth and yield using infrared thermometry. Proc. 21st Western Pecan Conf. 21:47-50.

Garrot, D.J., Jr., D.D. Fangmeier, S.H. Husman, M.W. Kilby, M.J. Ottman, D.T. Ray, S. Stedman, and J. Harper. 1990a. Irrigation scheduling using the crop water stress index in Arizona. Proc. Third Natl. Irrigation Symp. Amer. Soc. Agr. Eng. Publ. 04-90:281-286.

Garrot, D.J., Jr., D.T. Ray, D.D. Fangmeier, S.H. Husman, and M. Livingston. 1990b. Watermelon field irrigation management using the crop water stress index. Acta Hort. 278(2): 755-761.

Husman, S.H., D.J. Garrot, Jr., D.D. Fangmeier, and N.F. Oebker. 1990. Sweet corn irrigation scheduling using infrared thermometers and the crop water stress index. Univ. of Arizona, College of Agr. Veg. Rpt. Ser. P-82. p. 24-28.

Idso, S.B., R.D. Jackson, P.J. Pinter, Jr., R.J. Reginato, and J.L. Hatfield. 1981a. Normalizing the stress degree day concept for environmental variability. Agr. Met. 24:45-55.

Idso, S.B., R.J. Reginato, R.D. Jackson, and P.J. Pinter, Jr., 1981 b. Measuring yield-reducing plant water potential depressions in wheat by infrared thermometry. Irr. Sci. 2:205-212.

Idso, S.B. 1982. "Non-water-stressed baselines": A key to measuring and interpreting plant water stress. Agr. Met. 27:59-70.

Idso, S.B., R.J. Reginato, and J.W. Radin. 1982. Leaf diffusion resistance and photosynthesis in cotton as related to a foliage temperature based plant water stress index. Agr. Met. 27:27-34.

Idso., S.B. K.L. Klawsen, and M.G. Anderson. 1986. Foliage temperature: Effects of environmental factors with implications for plant water stress assessments in the $\mathrm{CO}_{2}$ /climate connection. Water Resources Res. 22:1702-1716.

Jackson, R.D., S.B. Idso, R.J. Reginato, and P.J. Pinter, Jr. 1981. Canopy temperature as a crop water stress indicator. Water Resources Res. 17:1133-1138.

Kilby, M.W. 1980. Fall irrigation of pecans. Pecan South 7(4):38-39.

Miyamoto, S. 1983. Consumptive water use of irrigated pecans. J. Amer. Soc. Hort. Sci. 108:676-681.

Nielsen, DC. 1990. Scheduling irrigations for soybeans with the crop water stress index (CWSI). Field Crops Res. 23:103-116.

Nielsen, D.C. and B.R. Gardner. 1987. Scheduling irrigations for corn with the crop water stress index (CWSI). Applied Agr. Res. 2:295-300.

Pinter, P.J., Jr., and R.J. Reginato. 1982. A thermal infrared technique for monitoring cotton water stress and scheduling irrigations. Trans. Amer. Soc. Agr. Eng. 25:1651-1655.

Sammis, T.W., W.R. Riley, and D.G. Lugg. 1986. Crop water stress index of pecans. Amer. Soc. Agr. Eng. Paper 86-2123.

Sammis, T.W., W.R. Riley, and D.G. Lugg. 1987. Scheduling irrigation on pecans using the crop water stress index. Proc. 21st Western Pecan Conf. 21:13-34.

SAS. 1991. SAS systems for linear models. 3rd ed. SAS Institute, Inc., Cary, N.C.

Wanjura, D.F., J.L. Hatfield, and D.R. Upchurch. 1990. Crop water stress index relationships with crop productivity. Irr. Sci. 11:93-99. 